\title{
White-Light-Activated Antibacterial Surfaces Generated by Synergy between Zinc Oxide Nanoparticles and Crystal Violet
}

\author{
Ekrem Ozkan, ${ }^{\dagger \oplus}$ Elaine Allan, ${ }^{\dagger}$ and Ivan P. Parkin ${ }^{*}{ }^{\dagger}$ \\ ${ }^{\dagger}$ Materials Chemistry Research Centre, Department of Chemistry, University College London, 20 Gordon Street, London WC1H \\ 0AJ, United Kingdom \\ ${ }^{\ddagger}$ Department of Microbial Diseases, UCL Eastman Dental Institute, University College London, 256 Gray’s Inn Road, London WC1X \\ 8LD, United Kingdom
}

\section{Supporting Information}

ABSTRACT: The prevalence of hospital-acquired infections (HAIs) caused by multidrug-resistant bacteria is a growing public health concern worldwide. Herein, a facile, easily scalable technique is reported to fabricate white-light-activated bactericidal surfaces by incorporating zinc oxide $(\mathrm{ZnO})$ nanoparticles and crystal violet $(\mathrm{CV})$ dye into poly(dimethylsiloxane). The effect of $\mathrm{ZnO}$ concentration on photobactericidal activity of $\mathrm{CV}$ is investigated, and we show that there is synergy between $\mathrm{ZnO}$ and $\mathrm{CV}$. These materials showed highly significant antibacterial activity when tested against Staphylococcus aureus and Escherichia coli under white light conditions. These surfaces have potential to be used in healthcare environments to decrease the impact of HAIs.

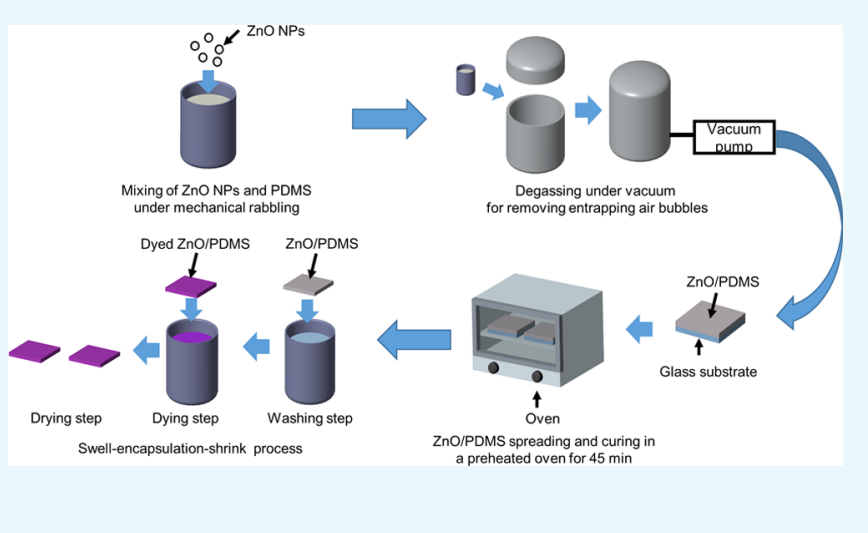

\section{INTRODUCTION}

Hospital-acquired infections (HAIs) are among the most serious complications of hospital care associated with extended duration of hospital stays, increased morbidity, and increased medical costs. According to the U.S. Center of Disease Control and Prevention, about 1 in 25 hospital patients acquires at least $1 \mathrm{HAI}$, equivalent to 722000 infections in the U.S. in 2011, and resulting in 75000 deaths during hospitalization. ${ }^{1}$ The treatment of these infections costs to the U.S. government app. \$35-\$45 billion per year. ${ }^{2}$ In the U.K., 300000 healthcareassociated infections occur each year and cost over $£ 1$ billion to the National Health Service (NHS). In healthcare facilities, $80 \%$ of infections are because of contaminated touch surfaces. Therefore, new antimicrobial surfaces need to be developed to minimize the risk of spreading bacteria.

A number of studies have reported novel and efficient antimicrobial surfaces including surfaces releasing microbicides, ${ }^{3,4}$ antibiotics, ${ }^{5,6}$ and quaternary ammonium salts ${ }^{7,8}$ and copper surfaces. ${ }^{9,10}$ Photodynamic therapy (PDT) has been raised as a promising alternative to current techniques. ${ }^{11}$ Antimicrobial photodynamic therapy, a type of PDT, is based on the use of nontoxic light-activated antimicrobial agents (LAAAs), known as photosensitizers, that are irradiated by a light source with an appropriate wavelength. ${ }^{12}$ In this process, these agents produce reactive oxygen species (ROS) that act on bacteria via multiple attack pathways including the oxidative destruction of cellular membranes, intracellular proteins, and DNA. Given the multiple targets of ROS, the emergence of bacterial resistance is extremely unlikely. ${ }^{13-15}$
Zinc oxide $(\mathrm{ZnO})$ is an inexpensive, wide band gap $(3.3 \mathrm{eV}$ at room temperature) semiconducting material that has excellent optical and electronic properties, finding a wide range of applications from field effect transistors to gas sensors and in dye-sensitized solar cells. ${ }^{16}$ Moreover, $\mathrm{ZnO}$ has the inherent advantage of showing antibacterial activities against a broad range of Gram-positive and Gram-negative bacteria. ${ }^{17-19}$ The antibacterial activity of $\mathrm{ZnO}$ has been well exploited under irradiation with light (UV or white light) and in the absence of light. ${ }^{19-23}$ Similar to that of LAAAs, the proposed mechanism of its antibacterial activity is thought to be via oxidative stress as a result of ROS production. ${ }^{24}$

Regarding surface application of LAAAs, it has been previously demonstrated that photosensitizers (e.g., crystal violet (CV) and methylene blue) can be successfully encapsulated into a variety of different polymers by a facile "swell-encapsulation-shrink" technique ${ }^{25-27}$ and these polymers demonstrate efficacious photoactivated antibacterial activity under irradiation with white light. Also, dyeimmobilized polymeric materials have demonstrated an enhanced photobactericidal activity when incorporated with different nanoparticles (NPs) (e.g., silver and gold). ${ }^{26,28,29}$ Even though these materials show potent photobactericidal activity, they include complex, labor-intensive, time-consuming synthesis of NPs. Also, these NPs can be implemented only to soft

Received: October 2, 2017

Accepted: February 20, 2018

Published: March 15, 2018 


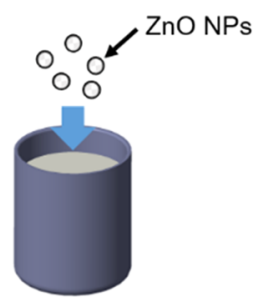

Mixing of ZnO NPs and PDMS

Under mechanical rabbling

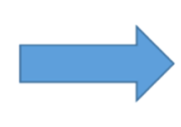

Dyed ZnO/PDMS

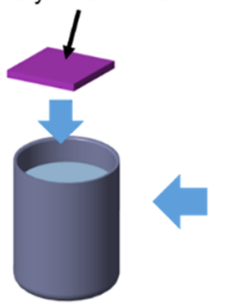

Washing step

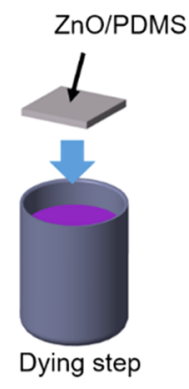

Dying step
PDMS spreading and curing in a preheated oven for $45 \mathrm{~min}$

Glass substrate
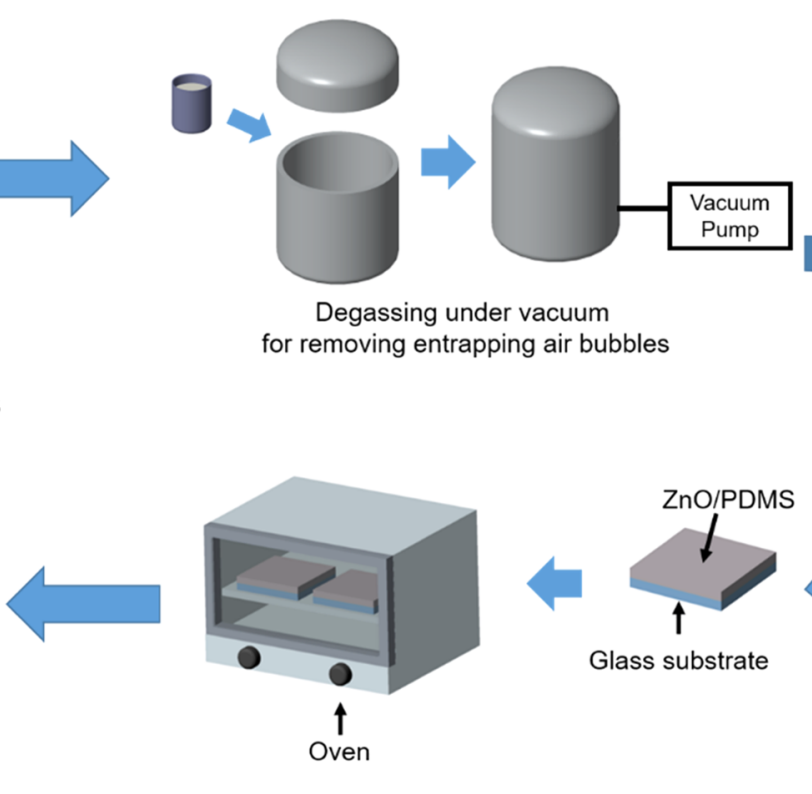

for removing entrapping air bubbles
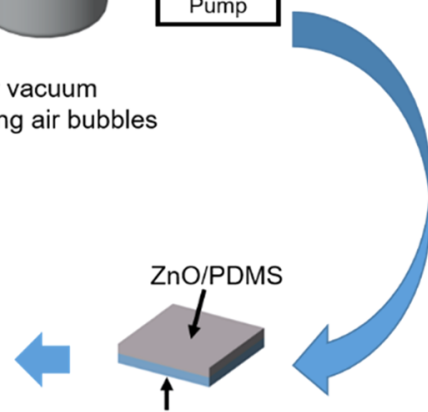

Swell-encapsulation-shrink process

Figure 1. Schematic view and process flow of the polymer paint containing $\mathrm{ZnO}$ and $\mathrm{CV}$.

materials such as polymers and silicones by the swellencapsulation-shrink process.

In our previous work, poly(dimethylsiloxane) (PDMS)/ZnO $\mathrm{NP}$ composites with 0.36 wt $\% \mathrm{ZnO}$ were fabricated through a solvent-aided dispersion process using chloroform as a solvent. $^{30}$ Then, $\mathrm{ZnO}$-incorporated polymer squares were coated with $\mathrm{CV}$ and these samples induced the lethal photosensitization of Escherichia coli within $4 \mathrm{~h}$ and Staphylococcus aureus within $1 \mathrm{~h}$ under white light conditions $(\sim 10$ 500 lux). ${ }^{30}$

In the present study, a similar, but a simpler, more versatile and scalable approach is reported for fabricating highly efficacious white-light-activated self-sterilizing surfaces based on three components $\mathrm{ZnO} \mathrm{NPs}, \mathrm{CV}$, and PDMS to overcome the aforementioned problems. The main objective of this study was to investigate whether the photobactericidal activity of CV is influenced by the $\mathrm{ZnO}$ content. Also, we utilized a lower white light intensity compared to that in the previous work ( 6500 lux $)$ in antimicrobial tests. The results showed that the synergistic combination of $\mathrm{CV}$ and $\mathrm{ZnO} \mathrm{NPs}$ led to superior antibacterial activity of the polymers.

\section{RESULTS AND DISCUSSION}

2.1. Materials Synthesis. $\mathrm{CV}$ and $\mathrm{ZnO} \mathrm{NPs}$ were incorporated into PDMS by a simple two-step procedure to fabricate a potent bactericidal polymer-nanocomposite (Figure 1). The first step involved mixing $\sim 60 \mathrm{~nm} \mathrm{ZnO} \mathrm{NPs} \mathrm{(see}$ Supporting Information, Figure S2a) with PDMS by mechanical rabbling on the basis of a series of PDMS/ZnO NPs with varying nanoparticle content, as shown in Table 1 . Then, the resultant milky polymer was degassed under vacuum to remove entrapped air bubbles. Finally, the polymer was cast on glass substrates and cured in a preheated oven at $100{ }^{\circ} \mathrm{C}$. Whereas PDMS is transparent, the $\mathrm{ZnO}$-embedded polymers are white (Figure 2).

In the second step, these modified polymers were coated with CV using a swell-encapsulation-shrink method. In this process, the polymer squares were dipped and left to swell in
Table 1. Polymer Matrices Embedded with the Photosensitizer Dye and Different ZnO NP Contents Represented by Various Sample IDs and Average Contact Angle (CA) Measurements $\left(^{\circ}\right) \pm$ Standard Deviation of the Samples

\begin{tabular}{lcccr}
\multicolumn{1}{c}{ sample ID } & $\begin{array}{c}\mathrm{ZnO} \\
(\mathrm{g})\end{array}$ & $\begin{array}{c}\text { PDMS } \\
(\mathrm{g})\end{array}$ & $\begin{array}{c}\text { photosensitizer } \\
(\mathrm{CV})\end{array}$ & $\begin{array}{c}\text { water contact } \\
\text { angle }\left(^{\circ}\right)\end{array}$ \\
PDMS (control) & & 10.0 & - & $97.0 \pm 1.80$ \\
$\mathrm{CV}$ & & 10.0 & + & $100.8 \pm 0.82$ \\
$0.5 \mathrm{ZnO}$ & 0.05 & 10.0 & - & $96.1 \pm 3.51$ \\
$0.5 \mathrm{ZnO}-\mathrm{CV}$ & 0.05 & 10.0 & + & $102.9 \pm 3.30$ \\
$1.0 \mathrm{ZnO}$ & 0.10 & 10.0 & - & $98.3 \pm 1.57$ \\
$1.0 \mathrm{ZnO}-\mathrm{CV}$ & 0.10 & 10.0 & + & $99.5 \pm 1.37$ \\
$5.0 \mathrm{ZnO}$ & 0.50 & 10.0 & - & $100.0 \pm 4.62$ \\
$5.0 \mathrm{ZnO}-\mathrm{CV}$ & 0.50 & 10.0 & + & $102.4 \pm 0.98$
\end{tabular}

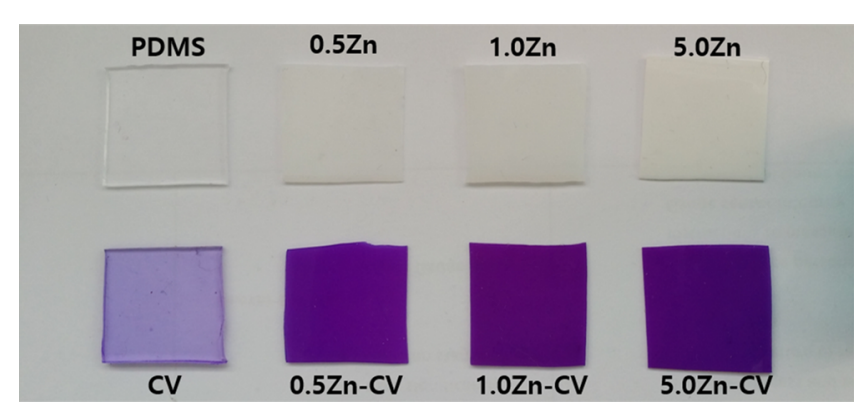

Figure 2. Photograph of the PDMS/ZnO samples with different nanoparticle contents $(0.5-5.0 \mathrm{wt} \%)$ : samples before (on the top) and after (on the bottom) the swell-encapsulation-shrink process.

$750 \mathrm{ppm} \mathrm{CV}$ solutions in acetone for $24 \mathrm{~h}$ under dark conditions. Acetone induced polymer swelling, allowing dye penetration through the polymer matrix. After removing from the solution, the swollen polymer had shrunk to its original dimensions as the remaining solvent evaporated. This method generated dark purple polymer squares, indicating an efficacious uptake of the dye onto the polymer surfaces (Figure 2). 

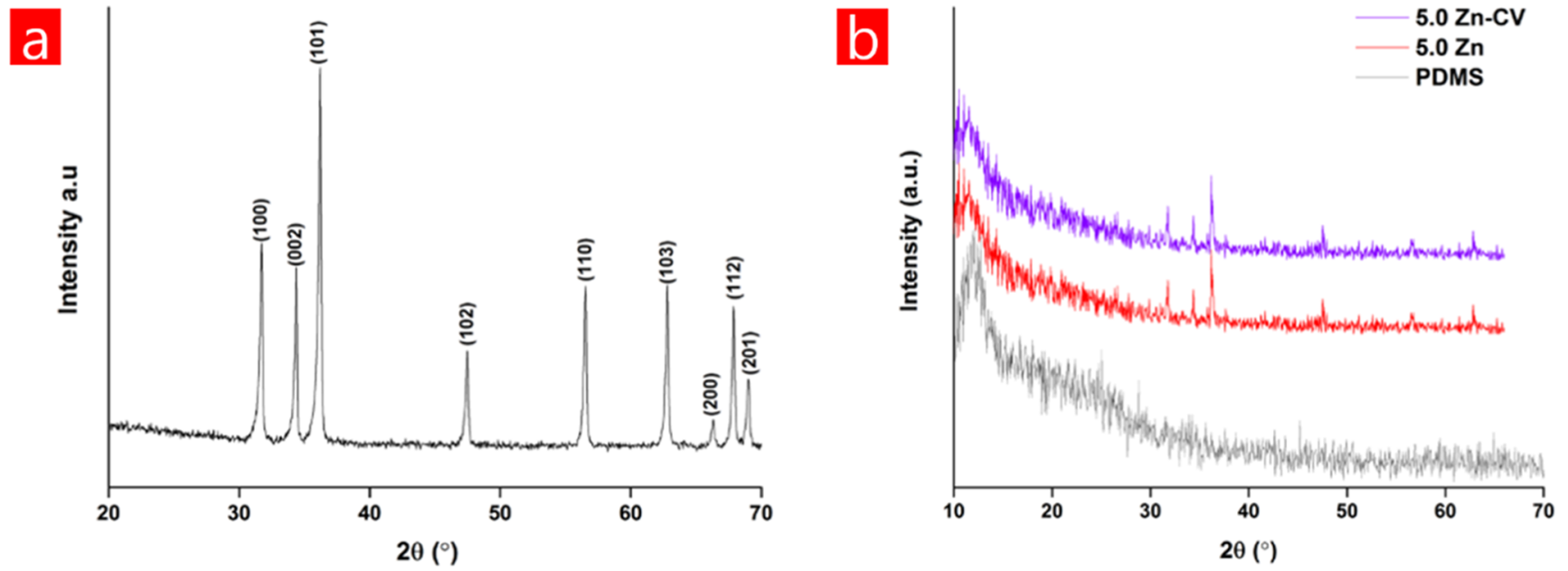

Figure 3. XRD patterns of (a) $\mathrm{ZnO}$ nanopowder and (b) PDMS, 5.0ZnO, and 5.0ZnO-CV. The peaks were indexed to a polycrystalline wurtzite structure.
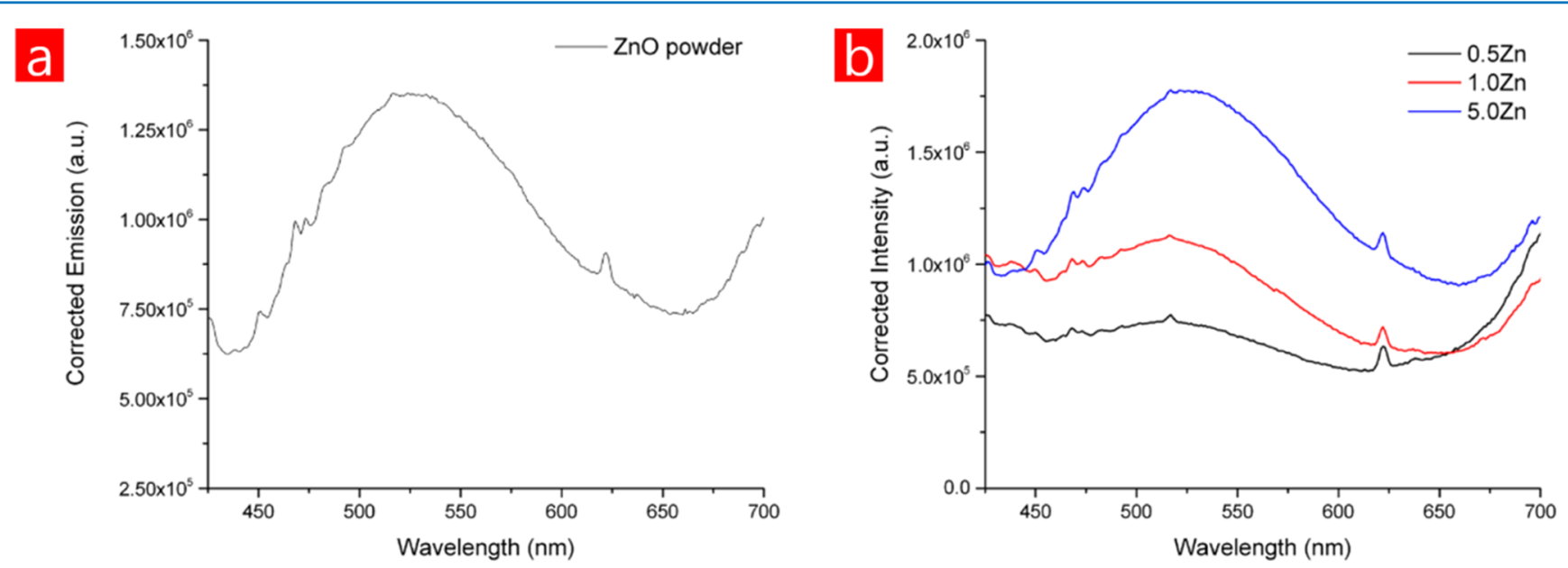

Figure 4. $\mathrm{PL}$ spectra of (a) $\mathrm{ZnO}$ nanopowder and (b) $\mathrm{ZnO} / \mathrm{PDMS}$ composites.

2.2. Material Characterization. Figure S3 shows the infrared absorbance spectra of the polymer films, from which no significant change was confirmed across the $\mathrm{ZnO} / \mathrm{PDMs}$ composite films from 0 to $5 \mathrm{wt} \%$ of $\mathrm{ZnO}$ nanoparticle concentration before and after the swell-encapsulation-shrink process. The similarity between the untreated and treated samples can be due to the strong PDMS absorbance bands and the low concentrations of dye present in the polymer samples. Consequently, the results indicate that the incorporation of $\mathrm{ZnO}$ NPs and $\mathrm{CV}$ in the silicones had no significant influence on the internal structures of the films within the detection limit of Fourier transform infrared (FT-IR).

The presence of the $\mathrm{ZnO}$ NPs was confirmed by X-ray diffraction (XRD), photoluminescence (PL) spectroscopy, and functional testing of the polymer films. The X-ray diffraction of neither the $0.5 \mathrm{ZnO}$ nor the $1.0 \mathrm{ZnO}$ sample displayed any discernible reflection because of the low density of the $\mathrm{ZnO}$ NPs embedded within the polymers, whereas phase-pure $\mathrm{ZnO}$ in the wurtzite crystal structure was appeared when $\mathrm{ZnO}$ concentration increased to $5.0 \mathrm{wt} \%$ (Figure 3b) (peaks at $2 \theta=$ $31.7,34.4,36.2,47.6$, and $56.5^{\circ}$ assigned to (100), (002), (101), (102), and (110) planes, respectively). Also, it can be seen that the incorporation of $\mathrm{CV}$ into the polymer does not impact the internal structure of the polymer film, in good agreement with the experimental results of Figure S3.

Photoluminescence measurements were made on the PDMSencapsulated materials with and without CV coating (Figure 4). The $\mathrm{ZnO}$-incorporated samples without $\mathrm{CV}$ displayed a clear, broad fluorescence band, peaking at ca. $520 \mathrm{~nm}$, increasing in intensity with increasing $\mathrm{ZnO}$ loading. This is in agreement with reported values for $\mathrm{ZnO}$ nanoparticles of this size and with a powder sample of $\mathrm{ZnO}$ measured ex situ of the PDMS. ${ }^{31,32}$ On coating with $\mathrm{CV}$, the $\mathrm{ZnO}$ emission band is overwhelmed by $\mathrm{CV}$ emission.

The treated PDMS samples were also characterized using UV-vis absorbance spectroscopy (Figure 5). The main and shoulder absorption peaks of PDMS containing $\mathrm{CV}$ alone are at $\lambda \approx 590$ and $533 \mathrm{~nm}$, respectively. The addition of ZnO NPs increased the maxima, intensity, and breadth of the $\mathrm{CV}$ peak, indicating that dye uptake was enhanced by increasing the $\mathrm{ZnO}$ concentration. This phenomenon has been demonstrated in another study in which gold nanoparticles enhanced the UVvisible absorption of toluidine blue. ${ }^{33}$ However, for 5.0ZnO$\mathrm{CV}$, the absorption reached its maximum as expected because $5.0 \mathrm{ZnO}-\mathrm{CV}$ was darker in color compared with any other CVcoated sample. The $\mathrm{CV}$ concentrations within the polymer were found to be $1.17 \times 10^{-4}, 6.64 \times 10^{-4}, 8.50 \times 10^{-4}$, and 

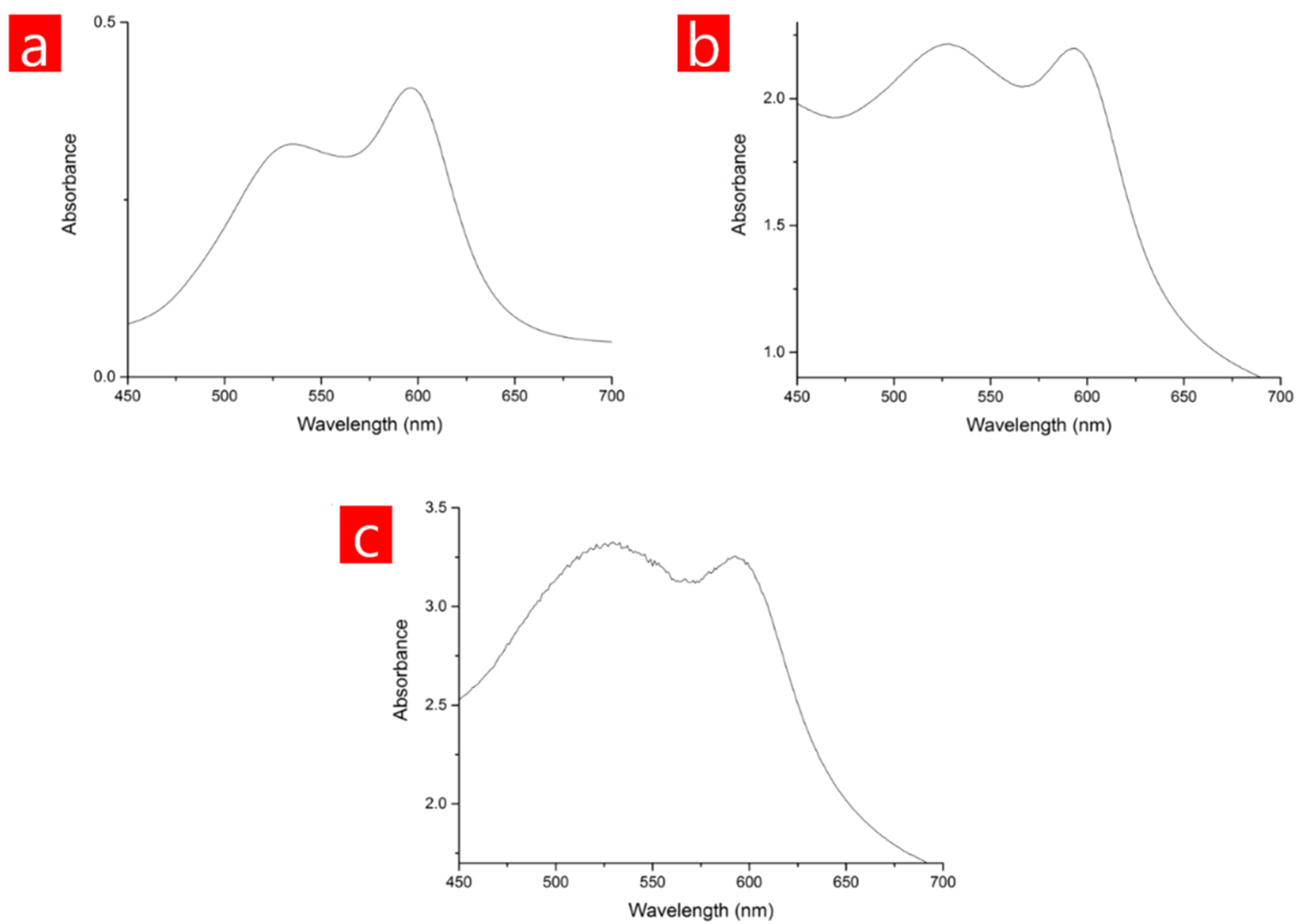

Figure 5. UV-visible absorbance spectra for (a) CV, (b) $0.5 \mathrm{ZnO}-\mathrm{CV}$, and (c) $1.0 \mathrm{ZnO}-\mathrm{CV}$.

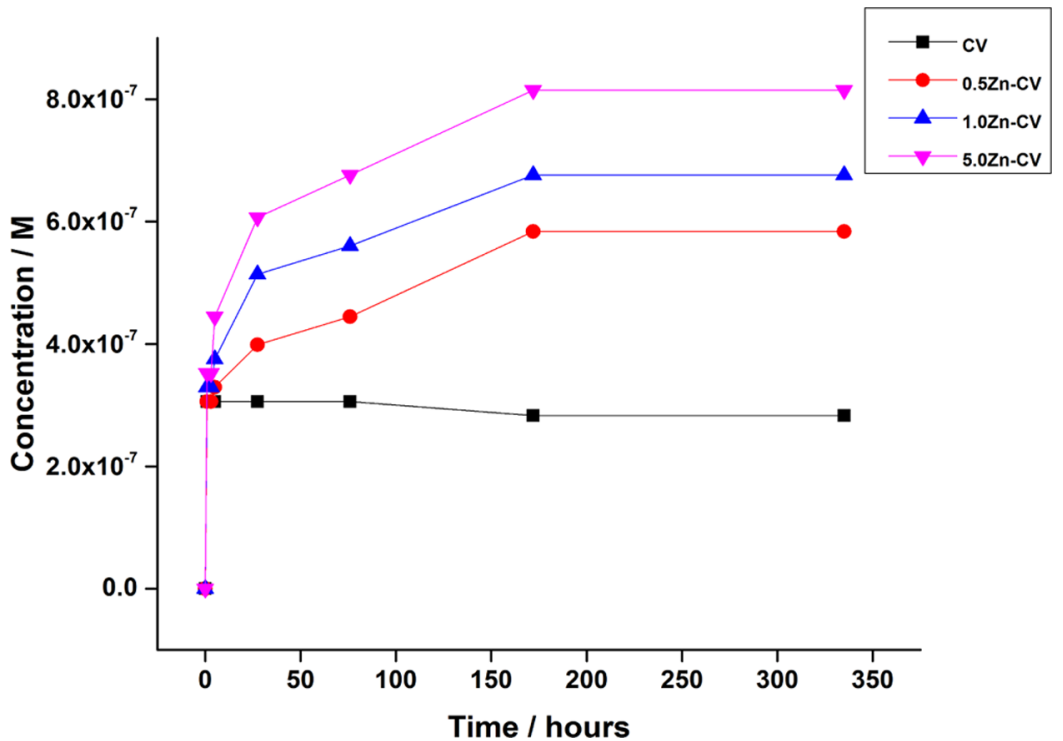

Figure 6. Leaching of crystal violet dye $\left(\mathrm{mol} \mathrm{dm}^{-3}\right)$ from the $\mathrm{CV}$-incorporated polymers into $\mathrm{PBS}$ solution at $37^{\circ} \mathrm{C}$ was measured as a function of time $(\mathrm{h})$.

$1.07 \times 10^{-3}$ for PDMS, $0.5 \mathrm{Zn}-\mathrm{CV}, 1.0 \mathrm{Zn}-\mathrm{CV}$, and $5.0 \mathrm{Zn}-$ $\mathrm{CV}$, respectively.

Moreover, a characteristic absorption peak at $375 \mathrm{~nm}$ for $\mathrm{ZnO}$ NPs suspended in water was seen in the range of UV (see Supporting Information, Figure S2b), indicating that ZnO NPs are UV-activated photocatalysts $(<385 \mathrm{~nm})$ and hence should not show significant antibacterial activity under white light conditions. However, when encapsulated in PDMS, there was no characteristic UV-vis peak of $\mathrm{ZnO}$ because of high nanoparticle concentrations.

Wetting properties of the samples were characterized by contact angle (CA) measurements using water as a test liquid. 


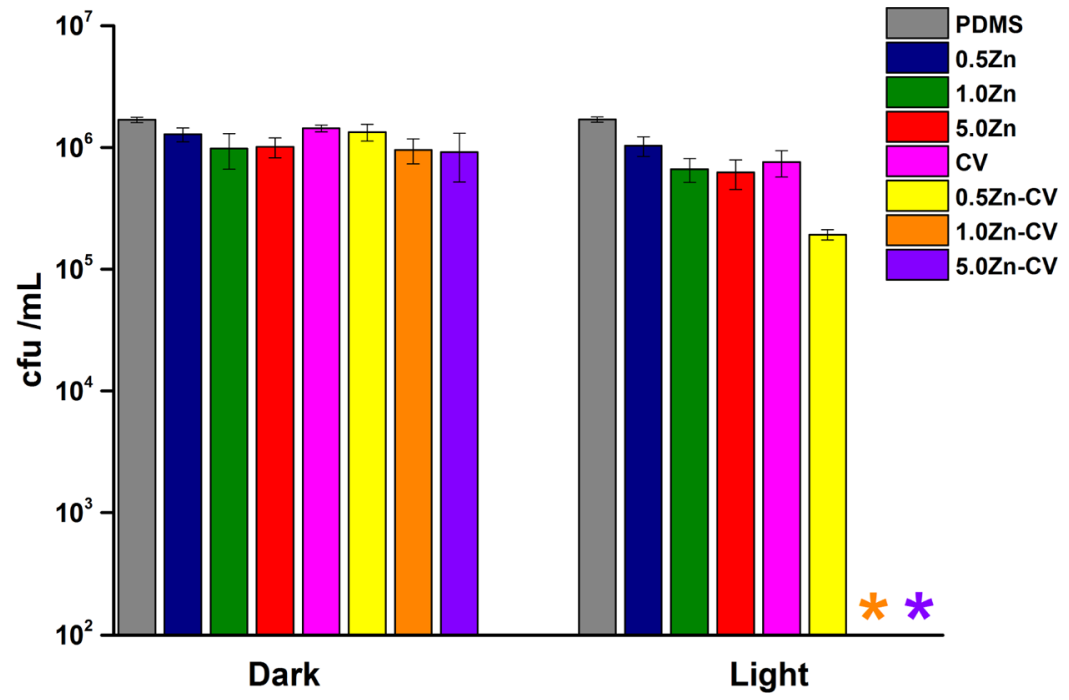

Figure 7. Number of viable colony counts of S. aureus 8325-4 on treated PDMS squares after incubation in the dark and in white light for 45 min. The orange and purple asterisks indicate $S$. aureus levels below detection limits.

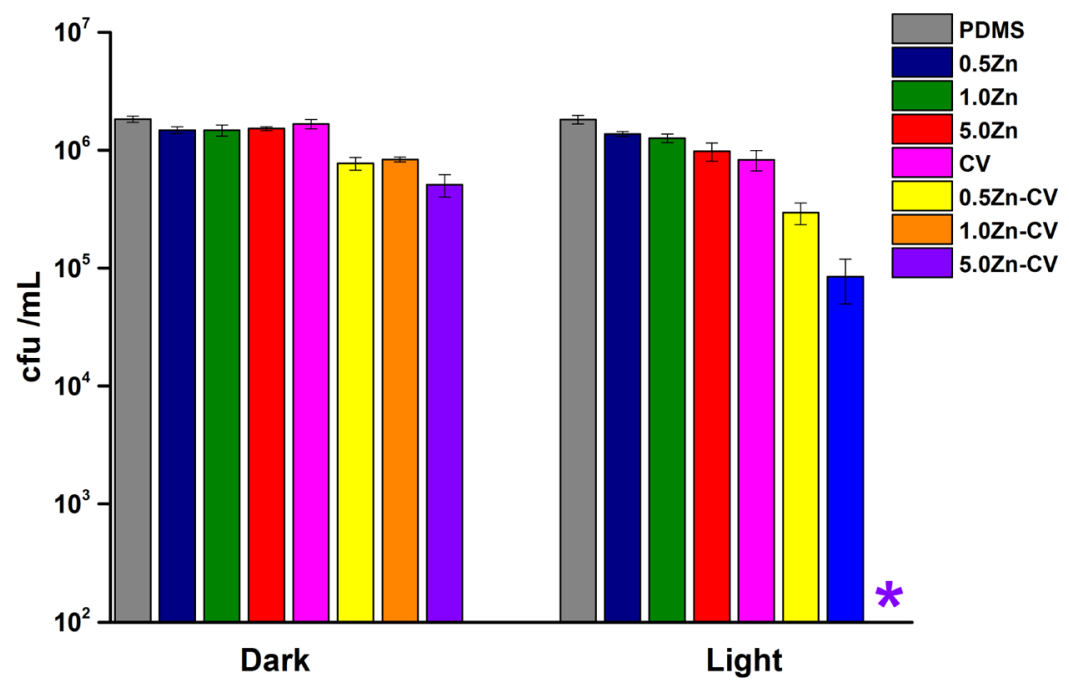

Figure 8. Number of viable colony counts of E. coli ATCC 25922 on treated PDMS squares after incubation in the dark and in white light for 45 min. The purple asterisk indicates $E$. coli levels below detection limits.

As demonstrated in Table 1, bare PDMS is inherently hydrophobic having a CA of $97.0 \pm 1.8^{\circ}$, whereas no significant difference in the wetting properties of the treated samples was observed, varying in contact angle by $\pm 6^{\circ}$.

To examine whether there was leaching of the dyeincorporated polymers, they were placed in $10 \mathrm{~mL}$ of phosphate-buffered saline (PBS) solution at $37{ }^{\circ} \mathrm{C}$ and the $\mathrm{CV}$ leachates were measured spectroscopically as a function of time (Figure 6). It can be seen that all of the CV-coated samples leached dye into PBS after $24 \mathrm{~h}$ and that the amount of $\mathrm{CV}$ leaching was correlated with increasing the nanoparticle weight. Over a period of more than $300 \mathrm{~h}$, the CV concentration of all of the samples plateaus at below $8.5 \times$ $10^{-7} \mathrm{M}$ and, overall, no further leaching was observed, indicating stability of the dye in the polymers. Crystal violet, a topical antiseptic, possesses antibacterial and antifungal properties. ${ }^{34}$ It is still listed by the World Health Organization even though new drugs have superseded its use in the medical field, and clinical trials showed its efficiency to treat infected wounds, superficial skin, and methicillin-resistant $S$. aureus infections. ${ }^{35,36}$ Hence, if there is significant leaching of the dye, it is not expected to show toxicity toward human cells.

In addition, a similar setup was used to detect whether the $\mathrm{ZnO}$-incorporated samples release nanoparticles into PBS solution. There was no observable change in the amount of leaching, color, or conductivity of the solution (data not shown), showing that the $\mathrm{ZnO}$ in the polymer matrix is more stable to leaching in contrast to $\mathrm{CV}$.

2.2.1. Antibacterial Investigation. The bactericidal properties of the following PDMS samples were examined against a Gram-positive bacterium, S. aureus 8325-4, and a Gramnegative bacterium, E. coli ATCC 25922, under dark and light conditions: undoped PDMS polymer (control), zinc oxide-incorporated PDMS ( $\mathrm{ZnO})$, crystal violet-coated PDMS (CV), 0.5\% ZnO-doped PDMS (0.5ZnO), 0.5\% ZnO-doped PDMS with $\mathrm{CV}(0.5 \mathrm{ZnO}-\mathrm{CV}), 1 \% \mathrm{ZnO}$-doped PDMS (1.0ZnO), $1 \% \mathrm{ZnO}$-doped PDMS with $\mathrm{CV}$ (1.0ZnO-CV), $5 \% \mathrm{ZnO}$-doped PDMS (5.0ZnO), and 5\% ZnO-doped PDMS with $\mathrm{CV}(5.0 \mathrm{ZnO}-\mathrm{CV})$. The photobactericidal activity of the CV-coated PDMS samples was activated with a white light 
source emitting an average light intensity of $6500 \pm 300$ lux at a distance of $25 \mathrm{~cm}$ from the samples (see Supporting Information, Figure S4). Also, a control sample set was tested in the dark for the same exposure times.

Figure 7 demonstrates the bactericidal activities of the samples against $S$. aureus after $45 \mathrm{~min}$ of incubation in the dark and in white light. Under dark conditions, none of the polymer samples showed statistically significant reduction in $S$. aureus numbers. Similarly, in white light, no significant killing of $S$. aureus was observed on the $0.5 \mathrm{ZnO}$ sample surface compared to that on the control sample. However, a greater reduction in bacterial numbers was apparent on the surfaces of both the $1.0 \mathrm{ZnO}$ and $5.0 \mathrm{ZnO}$ samples ( $P$-value $<0.01$ for both). Furthermore, the $0.5 \mathrm{ZnO}-\mathrm{CV}$ sample caused $\sim 1$ log reduction in the number of viable bacteria, with enhanced killing compared to that on the sample containing $\mathrm{CV}$ alone $(0.35$ $\log$ reduction). The effect of both the $1.0 \mathrm{ZnO}-\mathrm{CV}$ and $5.0 \mathrm{ZnO}-\mathrm{CV}$ samples was even more remarkable, reducing bacterial counts to below the detection limit $(\geq 4 \log , P$-value $=$ 0.002) in the light, within $45 \mathrm{~min}$.

The antibacterial properties of the same polymers were also investigated against $E$. coli under the same conditions but with a longer exposure time (Figure 8). In the dark, over a $90 \mathrm{~min}$ period, no statistically significant decrease in the numbers of $E$. coli was demonstrated by the samples containing $\mathrm{ZnO}$ NPs relative to that by the control polymer. On the other hand, except the polymer containing $\mathrm{CV}$ alone, all of the samples containing $\mathrm{ZnO}$ and coated with $\mathrm{CV}$ displayed statistically significant $(P$-value $<0.01)$ activity compared to that of the control sample.

After $90 \mathrm{~min}$ of white light exposure, the $0.5 \mathrm{ZnO}-\mathrm{CV}$ sample and the $1.0 \mathrm{ZnO}-\mathrm{CV}$ sample achieved $0.70 \mathrm{log}$ and 1.33 $\log$ reductions in the numbers of E. coli (Figure 8). Moreover, the $5.0 \mathrm{ZnO}-\mathrm{CV}$ sample displayed a highly significant reduction in bacterial numbers after 90 min of irradiation, with bacterial counts reduced to below the detection limit $(\geq 4 \log , P$-value $=$ 0.002).

The difference between the susceptibilities of the Grampositive ( $S$. aureus) and the Gram-negative (E. coli) bacteria is most probably because of the differences in their cell wall structures. ${ }^{37}$ Whereas Gram-positive bacteria possess a single thick peptidoglycan layer $(20-80 \mathrm{~nm})$, Gram-negative bacteria contain a thinner peptidoglycan layer $(7-8 \mathrm{~nm})$ but possess a second (outer) membrane, ${ }^{16}$ reducing the permeability of radicals and making them less susceptible to dye-coated polymeric surfaces. ${ }^{38,39}$ Overall, the results show that the polymer containing $\mathrm{ZnO}$ or $\mathrm{CV}$ alone does not possess potent antibacterial properties. Hence, it is required to combine both agents into the polymer to fabricate a superior self-sterilizing material that shows efficacious photobactericidal activity against both E. coli and S. aureus.

To evaluate the efficacy of these polymeric surfaces, their photobactericidal properties were compared with those of other antibacterial systems reported in the literature. For example, under white light conditions (40000 lux), protoporphyrin- and zinc protoporphyrin-grafted nylon fibers resulted in $5.6 \%$ reduction in the numbers of $S$. aureus, whereas they did not show significant killing of E. coli. ${ }^{40}$ Moreover, Sehmi et al. reported $\mathrm{CV}$ in combination with $\sim 18 \mathrm{~nm} \mathrm{ZnO}$ NPs incorporated in polyurethane squares. Upon illumination with a white light source $(6600 \pm 990 \mathrm{lux})$, these polymer samples caused lethal photosensitization of both E. coli and S. aureus in 1 and $4 \mathrm{~h}$, respectively. ${ }^{41}$
In our previous work, $\mathrm{CV}$ was encapsulated into PDMS squares in combination with $\mathrm{ZnO}$ NPs used in the present study, and they demonstrated significant antibacterial activity against $S$. aureus and $E$. coli in 1 and $4 \mathrm{~h}$, respectively, under white light conditions $(\sim 10500$ lux $) .^{42}$ These results validate the potent photobactericidal activity observed with the $5.0 \mathrm{ZnO}-\mathrm{CV}$ surfaces reported here, achieving decreases in bacterial numbers of greater than $4 \operatorname{logs}$ for both $S$. aureus and E. coli in only 45 and $90 \mathrm{~min}$, respectively.

These antibacterial materials can also be compared with other antibacterial surfaces that showed enhanced antibacterial activity. For example, at a much lower white light intensity of $\sim 500$ lux, significant lethal photodestruction of $S$. aureus and E. coli was achieved using polyurethane samples containing the combination of $\mathrm{CV}$ and $\mathrm{ZnO} \mathrm{NPs}(\sim 2-4 \mathrm{~nm}$ in size). This enhanced antibacterial efficacy may be ascribed to the small size of $\mathrm{ZnO}$ NPs because there is a correlation between the decreasing size of $\mathrm{ZnO} \mathrm{NPs}$ and their antibacterial activity. ${ }^{19,43,44}$ However, this method involves complex, laborious, time-consuming synthesis of the NPs and is only applicable to soft materials. Therefore, the proposed method in this study outperforms its counterparts in many aspects such as its easy fabrication, the low-cost materials utilized, and the material's high versatility for being coated on a wide range of substrates (e.g. metal, glass, paper, and soft polymer plates) (see Supporting Information, Figure S5).

The antibacterial behavior of $\mathrm{CV}$ is well established. Upon light activation of the dye, two different photochemical reaction pathways occur simultaneously: one generates hydroxyl radicals $\left({ }^{\bullet} \mathrm{OH}\right)$ and superoxide ions $\left(\mathrm{O}_{2}{ }^{--}\right)$through the electron transfer process (type I) and the other generates singlet oxygen $\left({ }^{1} \mathrm{O}_{2}\right)$ through energy transfer (type II). ${ }^{45}$ Photogenerated ROS can attack bacteria via a non-site-specific multiple attack mechanism (unlike antibiotics, which usually have a singlet target) including the disruption of cellular membranes and DNA by means of oxidative damage, making bacteria unlikely to develop resistance because resistance normally occurs when a bactericide has a single target. ${ }^{14,46,47}$

In contrast to that of $\mathrm{CV}$, the killing mechanism of $\mathrm{ZnO}$ is still unclear, but there are various mechanisms proposed in the literature, including the production of ROS, ${ }^{19,20,48-52}$ the release of zinc ions, ${ }^{21,48,53,54}$ and the accumulation of NPs in the bacterial cytoplasm and on the outer membrane of Gramnegative bacteria. ${ }^{19}$ Some studies showing significant antibacterial activity of $\mathrm{ZnO}$ in the dark attributed this to the release of zinc ions from a $\mathrm{ZnO}$ suspension, which penetrate into the bacteria, damaging DNA and resulting in cell death. ${ }^{23,55,56}$ However, there are many studies indicating that the concentrations of released $\mathrm{Zn}^{2+}$ ions were not high enough to cause nanotoxicity. ${ }^{19,20,57,58}$ Lakshmi et al. proved that its antibacterial activity is mainly attributed to ROS in the dark ${ }^{59}$ rather than release of zinc ions (zinc ion dissolution) and $\mathrm{ZnO}$ internalization. $^{22,23,60,61}$ The presence of surface defects on $\mathrm{ZnO}$ NPs can generate ROS under lower-energy-light illumination (i.e., visible light). Previous study has demonstrated that the encapsulation of $\mathrm{ZnO}$ in combination with $\mathrm{CV}$ into polyurethane can increase the photobactericidal activity of the dye via both type I and type 2 pathways, ${ }^{41}$ which is in good agreement with the data presented here.

Regarding real-world applications, antimicrobial materials should to be durable, environmentally friendly, and not harmful to humans. ${ }^{62}$ Therefore, it is imperative that the dye incorporated in the polymer does not leach significantly or 
rub off upon contact with hands or disinfectant wipes that are often used to reduce the risk of the spread of infection. We have demonstrated that the dye-coated samples proved to be stable to contact with aqueous solution at $37^{\circ}$. The amount of dye leached from the samples was relatively small relative to the concentration $(20000 \mathrm{ppm})$, resulting in dermal irradiation or sensitization over an extended period of clinical assessment. ${ }^{36}$ Furthermore, to determine the stability of the modified polymers against standard hospital hygiene regime conditions, they were vigorously wiped with Clinell wipes that are utilized to clean hard surfaces on the wards in University College London Hospital NHS Trust hospitals. There was no visual evidence of dye removal from the modified polymer after rigorous wiping with $70 \%$ alcohol, proving its robustness against our standard hospital cleaning protocol and, hence, transmission of dye upon touching is unlikely. Similarly, the leaching of $\mathrm{ZnO}$ NPs and their transfer by human contact is minimal because we have shown that they are well embedded into the polymer. $\mathrm{ZnO}$ NPs have been widely utilized in the cosmetics and food industry, and their toxicity in humans has been extensively investigated, with the conclusion that it depends on many factors such as their size, shape, route of administration, and dosage. Studies have showed that their penetration through skin is improbable although other routes of administration of these nanoparticles can demonstrate harmful effects at high doses $\left(>100 \mu \mathrm{g} \mathrm{mL}{ }^{-1}\right) .{ }^{63,64}$

\section{CONCLUSIONS}

In this study, $\mathrm{ZnO}$ NPs have been successfully embedded with different nanoparticle concentrations in PDMS, followed by incorporating $\mathrm{CV}$ using a simple swell-encapsulation-shrink process to fabricate white-light-activated antibacterial surfaces. The $\mathrm{ZnO} / \mathrm{CV}$ composites possess superior antibacterial activities that are dependent upon the concentration of zinc in the polymer films. Among them, the $5.0 \mathrm{ZnO}-\mathrm{CV}$ composite is proved to be one of the most efficacious antibacterial polymer surfaces developed to date, active in light conditions relevant to U.K. hospitals and exhibiting lethal photosensitization of $S$. aureus in just $45 \mathrm{~min}$ and of $E$. coli in just $90 \mathrm{~min}$, with a minimum of a $4 \mathrm{log}$ reduction in the numbers of both bacteria. Because release or transmission of dye and nanoparticle upon using this polymer coating is improbable, it has potential applications from healthcare settings (e.g., doors and hospital bed rails) to electronic devices (e.g., tablet and mobile phone covers) to help reduce bacterial surface contamination and thus reduce the risk of the spread of infection.

\section{MATERIALS AND METHODS}

4.1. Chemicals and Substrates. All chemicals used in this study were purchased from Sigma-Aldrich Chemical Co. except for acetone (VWR, U.K.). The PDMS prepolymer and curing agent (SYLGARD 184) were purchased from Dow Corning Corporation.

4.2. Materials Synthesis. 4.2.1. Preparation of ZnO NPs/ PDMS Composites. Polymer/nanoparticle composites with various $\mathrm{ZnO}$ contents $(0,0.5,1$, and 5 wt $\%)$ were produced. The appropriate amount of $\mathrm{ZnO}$ NPs was dispersed in PDMS (monomer/crosslink $=10: 1$ in mass), and the mixture was homogenized by hand-stirring. Afterward, the slurry was degassed in a desiccator for $15 \mathrm{~min}$, followed by casting on glass substrates and they were cured in a preheated oven (100 ${ }^{\circ} \mathrm{C}$ ) for $45 \mathrm{~min}$. After the cooling, the polymer sheets were peeled off from the substrates and were cut into smaller pieces (squares $2.0 \mathrm{~cm} \times 2.0 \mathrm{~cm}$ ).

4.2.2. Preparation of Polymers with Embedded Crystal Violet. Bare PDMS and $\mathrm{ZnO}$-incorporated samples were coated with $\mathrm{CV}$ (by placing $2 \mathrm{~cm} \times 2 \mathrm{~cm}$ squares into $750 \mathrm{ppm}$ solutions of $\mathrm{CV}$ in acetone for $24 \mathrm{~h}$ ) before removal, washed, and air-dried (24 h).

4.3. Material Characterization. Transmission electron microscopy (TEM) images were taken using JEOL JEM $1200 E X$ with a 4 megapixel Gatan Orius SC200 charge-coupled device camera at an acceleration voltage of $120 \mathrm{kV}$.

The infrared absorbance spectra of the modified polymer samples were recorded within the range of 1000-4000 $\mathrm{cm}^{-1}$ with an accumulation of 16 scans per sample using a Bruker Platinum ATR.

X-ray diffraction patterns of the modified samples were recorded using a Stoe diffractometer with monochromated Mo $\mathrm{K} \alpha_{1}$ radiation $(\lambda=0.7093 \AA)$ in transmission mode over the angle range $20-70^{\circ} / 2 \theta^{\circ}$.

The photoluminescence (PL) spectra of the treated samples were recorded using a Fluoromax 4.0 Jobin Yvon Horiba spectrofluorometer.

UV-vis absorption spectra of the $\mathrm{ZnO} \mathrm{NP}$ aqueous suspension and $\mathrm{CV}$-coated polymer samples were measured using a PerkinElmer Lambda $950 \mathrm{UV}-$ vis spectrometer over a range of $200-800 \mathrm{~nm}$ (full range not shown).

Water contact angle measurements were performed using an FTA-1000 drop shape instrument. A $3 \mu \mathrm{L}$ water droplet was dropped onto the surface of the samples, and the contact angle of the droplet was calculated using FTA32 software.

4.4. Functional Testing. 4.4.1. Leaching Test. The stability of the CV-coated PDMS polymers in solution was examined by immersing $2 \mathrm{~cm}^{2}$ squares in phosphate-buffered saline (PBS) $(10 \mathrm{~mL})$ at $37{ }^{\circ} \mathrm{C}$ for an extended period of time. The concentration of $\mathrm{CV}$ that leached into the PBS solution was recorded periodically using UV-vis spectroscopy (596 nm, Pharmacia Biotech Ultrospec 2000) and by comparing the absorbance of PBS at $596 \mathrm{~nm}$ with a CV calibration curve.

4.4.2. Dye Adherence Testing. All samples containing crystal violet were wiped rigorously with a $70 \%$ isopropyl alcohol wipe (AZOwipeTM, Synergy Health) to determine whether the dye adhered to the sample surface under standard cleaning regimes.

4.4.3. Bactericidal Assay. The following polymer samples (2 $\mathrm{cm} \times 2 \mathrm{~cm}$ ) were utilized in the bactericidal assays: bare PDMS polymer (control), zinc oxide-incorporated PDMS ( $\mathrm{ZnO})$, crystal violet-coated PDMS (CV), 0.5\% ZnO-doped PDMS (0.5ZnO), 0.5\% ZnO-doped PDMS with $\mathrm{CV}$ (0.5ZnO-CV), $1 \% \mathrm{ZnO}$-doped PDMS (1.0ZnO), 1\% ZnO-doped PDMS with $\mathrm{CV}(1.0 \mathrm{ZnO}-\mathrm{CV}), 5 \% \mathrm{ZnO}$-doped PDMS (5.0ZnO), and 5\% $\mathrm{ZnO}$-doped PDMS with $\mathrm{CV}(5.0 \mathrm{ZnO}-\mathrm{CV})$. These samples were evaluated against E. coli ATCC 25922 and S. aureus 83254. These organisms were stored at $-70{ }^{\circ} \mathrm{C}$ in brain-heartinfusion broth (BHI, Oxoid) containing 20\% (v/v) glycerol and propagated on either MacConkey agar (Oxoid Ltd.) in the case of E. coli or mannitol salt agar (Oxoid Ltd.) in the case of $S$. aureus, for a maximum of two subcultures at intervals of 2 weeks.

A single colony of either E. coli or S. aureus was cultured in BHI broth $(10 \mathrm{~mL})$ for $17 \mathrm{~h}$, shaking at $37{ }^{\circ} \mathrm{C}$. The bacterial pellet was harvested by centrifugation $\left(20^{\circ} \mathrm{C}, 4000 \mathrm{rpm}, 5\right.$ min) and washed in PBS $(10 \mathrm{~mL})$. After centrifugation again under the same conditions, the bacteria were resuspended in PBS $(10 \mathrm{~mL})$. The washed bacterial suspension was then 
diluted 1 in 1000 in PBS to give an inoculum of $\sim 10^{6} \mathrm{CFU}$ $\mathrm{mL}^{-1}$.

Duplicates of each polymer sample were inoculated with 25 $\mu \mathrm{L}$ of the inoculum and covered with a sterile cover slip $(1.8 \mathrm{~cm}$ $\times 1.8 \mathrm{~cm}$ ). The samples were then irradiated for the required time period using a white light source that emits an average light intensity of $6500 \pm 300$ lux at a distance of $25 \mathrm{~cm}$ from the samples. A further set of samples (in duplicate) was maintained under dark conditions for the duration of the irradiation time.

Post irradiation, the inoculated samples and cover slips were transferred to a tube containing PBS $(5 \mathrm{~mL})$ and vortexed (60 s). The neat suspension and 10 -fold serial dilutions were plated on the appropriate agar. The plates were incubated aerobically for $24 \mathrm{~h}$ (E. coli) or for $48 \mathrm{~h}$ (S. aureus) at $37^{\circ} \mathrm{C}$, and the were colonies enumerated to determine the number of viable bacteria. The bacterial numbers in the inoculum were also determined in each experiment by viable colony counting. Each experiment contained two technical replicates, and the experiment was reproduced three times. The Mann-Whitney $\mathrm{U}$ test was used to analyze the statistical significance of the data.

\section{ASSOCIATED CONTENT}

\section{S Supporting Information}

The Supporting Information is available free of charge on the ACS Publications website at DOI: 10.1021/acsomega.7b01473.

Chemical structures of the used materials, modified different substrates, TEM image and UV-vis spectrum of $\mathrm{ZnO} \mathrm{NPs}$, FT-IR of $\mathrm{ZnO} / \mathrm{PDMS}$ films, and UV-vis spectrum of the light source used in the work (PDF)

\section{AUTHOR INFORMATION}

\section{Corresponding Author}

*E-mail: i.p.parkin@ucl.ac.uk.

\section{ORCID 1}

\section{Ekrem Ozkan: 0000-0003-1689-1576}

\section{Author Contributions}

The manuscript was written through contributions of all authors. All authors have given approval to the final version of the manuscript.

\section{Notes}

The authors declare no competing financial interest.

\section{ACKNOWLEDGMENTS}

E.O. would like to thank Dr. William Peveler for his help with PL.

\section{REFERENCES}

(1) Multistate Point-Prevalence Survey of Health Care-Associated Infections-NEJM. http://www.nejm.org/doi/full/10.1056/ NEJMoa1306801 (accessed Dec 29, 2015).

(2) The Direct medical costs of healthcare-associated infections in U.S. hospitals and the benefits of prevention-11550|Library Collectionllocalhost. http://stacks.cdc.gov/view/cdc/11550/ (accessed Dec 29, 2015).

(3) Edmiston, C. E., Jr.; Daoud, F. C.; Leaper, D. Is There an Evidence-Based Argument for Embracing an Antimicrobial (Triclosan)-Coated Suture Technology to Reduce the Risk for Surgical-Site Infections?: A Meta-Analysis. Surgery 2013, 154, 89-100.

(4) Williams, D. L.; Sinclair, K. D.; Jeyapalina, S.; Bloebaum, R. D. Characterization of a Novel Active Release Coating to Prevent Biofilm Implant-Related Infections. J. Biomed. Mater. Res., Part B 2013, 101, 1078-1089.
(5) Darouiche, R. O. Antimicrobial Approaches for Preventing Infections Associated with Surgical Implants. Clin. Infect. Dis. 2003, 36, 1284-1289.

(6) Gollwitzer, H.; Thomas, P.; Diehl, P.; Steinhauser, E.; Summer, B.; Barnstorf, S.; Gerdesmeyer, L.; Mittelmeier, W.; Stemberger, A. Biomechanical and Allergological Characteristics of a Biodegradable poly(D,L-Lactic Acid) Coating for Orthopaedic Implants. J. Orthop. Res. 2005, 23, 802-809.

(7) Lin, S.; Wu, J.; Jia, H.; Hao, L.; Wang, R.; Qi, J. Facile Preparation and Antibacterial Properties of Cationic Polymers Derived from 2(Dimethylamino)ethyl Methacrylate. RSC Adv. 2013, 3, 20758.

(8) Wang, H.; Synatschke, C. V.; Raup, A.; Jérôme, V.; Freitag, R.; Agarwal, S. Oligomeric Dual Functional Antibacterial Polycaprolactone. Polym. Chem. 2014, 5, 2453.

(9) Salgado, C. D.; Sepkowitz, K. A.; John, J. F.; Cantey, J. R.; Attaway, H. H.; Freeman, K. D.; Sharpe, P. A.; Michels, H. T.; Schmidt, M. G. Copper Surfaces Reduce the Rate of HealthcareAcquired Infections in the Intensive Care Unit. Infect. Control Hosp. Epidemiol. 2013, 34, 479-486.

(10) Ozkan, E.; Crick, C. C.; Taylor, A.; Allan, E.; Parkin, I. P. Copper-Based Water Repellent and Antibacterial Coatings by Aerosol Assisted Chemical Vapour Deposition. Chem. Sci. 2016, 7, 5126-5131.

(11) Wainwright, M.; Crossley, K. B. Photosensitising Agentscircumventing Resistance and Breaking down Biofilms: A Review. Int. Biodeterior. Biodegrad. 2004, 53, 119-126.

(12) Dai, T.; Huang, Y.-Y.; Hamblin, M. R. Photodynamic Therapy for Localized Infections-State of the Art. Photodiagn. Photodyn. Ther. 2009, 6, 170-188.

(13) Noimark, S.; Dunnill, C. W.; Parkin, I. P. Shining Light on Materials-A Self-Sterilising Revolution. Adv. Drug Delivery Rev. 2013, $65,570-580$.

(14) Kohanski, M. A.; Dwyer, D. J.; Hayete, B.; Lawrence, C. A.; Collins, J. J. A Common Mechanism of Cellular Death Induced by Bactericidal Antibiotics. Cell 2007, 130, 797-810.

(15) Perni, S.; Piccirillo, C.; Pratten, J.; Prokopovich, P.; Chrzanowski, W.; Parkin, I. P.; Wilson, M. The Antimicrobial Properties of Light-Activated Polymers Containing Methylene Blue and Gold Nanoparticles. Biomaterials 2009, 30, 89-93.

(16) Noimark, S.; Weiner, J.; Noor, N.; Allan, E.; Williams, C. K.; Shaffer, M. S. P.; Parkin, I. P. Dual-Mechanism Antimicrobial Polymer$\mathrm{ZnO}$ Nanoparticle and Crystal Violet-Encapsulated Silicone. Adv. Funct. Mater. 2015, 25, 1367-1373.

(17) Zhang, L.; Jiang, Y.; Ding, Y.; Povey, M.; York, D. Investigation into the Antibacterial Behaviour of Suspensions of $\mathrm{ZnO}$ Nanoparticles (ZnO Nanofluids). J. Nanopart. Res. 2007, 9, 479-489.

(18) Hoseinzadeh, E.; Alikhani, M.-Y.; Samarghandi, M.-R.; ShirzadSiboni, M. Antimicrobial Potential of Synthesized Zinc Oxide Nanoparticles against Gram Positive and Gram Negative Bacteria. Desalin. Water Treat. 2014, 52, 4969-4976.

(19) Raghupathi, K. R.; Koodali, R. T.; Manna, A. C. Size-Dependent Bacterial Growth Inhibition and Mechanism of Antibacterial Activity of Zinc Oxide Nanoparticles. Langmuir 2011, 27, 4020-4028.

(20) Applerot, G.; Lipovsky, A.; Dror, R.; Perkas, N.; Nitzan, Y.; Lubart, R.; Gedanken, A. Enhanced Antibacterial Activity of Nanocrystalline ZnO Due to Increased ROS-Mediated Cell Injury. Adv. Funct. Mater. 2009, 19, 842-852.

(21) Li, M.; Zhu, L.; Lin, D. Toxicity of ZnO Nanoparticles to Escherichia coli: Mechanism and the Influence of Medium Components. Environ. Sci. Technol. 2011, 45, 1977-1983.

(22) Brayner, R.; Ferrari-Iliou, R.; Brivois, N.; Djediat, S.; Benedetti, M. F.; Fiévet, F. Toxicological Impact Studies Based on Escherichia coli Bacteria in Ultrafine ZnO Nanoparticles Colloidal Medium. Nano Lett. 2006, 6, 866-870.

(23) Li, Y.; Niu, J.; Zhang, W.; Zhang, L.; Shang, E. Influence of Aqueous Media on the ROS-Mediated Toxicity of ZnO Nanoparticles toward Green Fluorescent Protein-Expressing Escherichia coli under UV-365 Irradiation. Langmuir 2014, 30, 2852-2862.

(24) Li, Y.; Zhang, W.; Niu, J.; Chen, Y. Mechanism of Photogenerated Reactive Oxygen Species and Correlation with the 
Antibacterial Properties of Engineered Metal-Oxide Nanoparticles. ACS Nano 2012, 6, 5164-5173.

(25) Noimark, S.; Bovis, M.; MacRobert, A. J.; Correia, A.; Allan, E.; Wilson, M.; Parkin, I. P. Photobactericidal Polymers; the Incorporation of Crystal Violet and Nanogold into Medical Grade Silicone. RSC Adv. 2013, 3, 18383.

(26) Sehmi, S. K.; Noimark, S.; Bear, J. C.; Peveler, W. J.; Bovis, M.; Allan, E.; MacRobert, A. J.; Parkin, I. P. Lethal Photosensitisation of Staphylococcus aureus and Escherichia coli Using Crystal Violet and Zinc Oxide-Encapsulated Polyurethane. J. Mater. Chem. B 2015, 3, 64906500.

(27) Naik, A. J. T.; Ismail, S.; Kay, C.; Wilson, M.; Parkin, I. P. Antimicrobial Activity of Polyurethane Embedded with Methylene Blue, Toluidene Blue and Gold Nanoparticles against Staphylococcus aureus; Illuminated with White Light. Mater. Chem. Phys. 2011, 129, $446-450$.

(28) Noimark, S.; Dunnill, C. W.; Kay, C. W. M.; Perni, S.; Prokopovich, P.; Ismail, S.; Wilson, M.; Parkin, I. P. Incorporation of Methylene Blue and Nanogold into Polyvinyl Chloride Catheters; a New Approach for Light-Activated Disinfection of Surfaces. J. Mater. Chem. 2012, 22, 15388.

(29) Bovis, M. J.; Noimark, S.; Woodhams, J. H.; Kay, C. W. M.; Weiner, J.; Peveler, W. J.; Correia, A.; Wilson, M.; Allan, E.; Parkin, I. P.; MacRobert, A. J. Photosensitisation Studies of Silicone Polymer Doped with Methylene Blue and Nanogold for Antimicrobial Applications. RSC Adv. 2015, 5, 54830-54842.

(30) Ozkan, E.; Tunali Ozkan, F.; Allan, E.; Parkin, I. P. The Use of Zinc Oxide Nanoparticles to Enhance the Antibacterial Properties of Light-Activated Polydimethylsiloxane Containing Crystal Violet. RSC Adv. 2015, 5, 8806-8813.

(31) Rodnyi, P. A.; Khodyuk, I. V. Optical and Luminescence Properties of Zinc Oxide (Review). Opt. Spectrosc. 2011, 111, 776785.

(32) Irimpan, L.; Nampoori, V. P. N.; Radhakrishnan, P.; Deepthy, A.; Krishnan, B. Size Dependent Fluorescence Spectroscopy of Nanocolloids of ZnO. J. Appl. Phys. 2007, 102, No. 063524.

(33) Kitching, H.; Kenyon, A. J.; Parkin, I. P. The Interaction of Gold and Silver Nanoparticles with a Range of Anionic and Cationic Dyes. Phys. Chem. Chem. Phys. 2014, 16, 6050.

(34) National Biochemicals Corporation, Crystal Violet. http//www. nationalbiochem.com/pdf/pis/MC3886\%20PS.pdf (accessed May 22, 2014).

(35) Kawamoto, K.; Senda, N.; Shimada, K.; Ito, K.; Hirano, Y.; Murai, S. Antibacterial Effect of Yellow He-Ne Laser Irradiation with Crystal Violet Solution on Porphyromonas gingivalis: An Evaluation Using Experimental Rat Model Involving Subcutaneous Abscess. Lasers Med. Sci. 2000, 15, 257-262.

(36) Saji, M.; Taguchi, S.; Uchiyama, K.; Osono, E.; Hayama, N.; Ohkuni, H. Efficacy of Gentian Violet in the Eradication of MethicillinResistant Staphylococcus aureus from Skin Lesions. J. Hosp. Infect. 1995, 31, 225-228.

(37) Noimark, S.; Bovis, M.; MacRobert, A. J.; Correia, A.; Allan, E.; Wilson, M.; Parkin, I. P. Photobactericidal Polymers; the Incorporation of Crystal Violet and Nanogold into Medical Grade Silicone. RSC Adv. 2013, 3, 18383.

(38) Noimark, S.; Allan, E.; Parkin, I. P. Light-Activated Antimicrobial Surfaces with Enhanced Efficacy Induced by a DarkActivated Mechanism. Chem. Sci. 2014, 5, 2216.

(39) Sehmi, S. K.; Noimark, S.; Weiner, J.; Allan, E.; MacRobert, A. J.; Parkin, I. P. Potent Antibacterial Activity of Copper Embedded into Silicone and Polyurethane. ACS Appl. Mater. Interfaces 2015, 7, 22807-22813.

(40) Bozja, J.; Sherrill, J.; Michielsen, S.; Stojiljkovic, I. PorphyrinBased, Light-Activated Antimicrobial Materials. J. Polym. Sci., Part A: Polym. Chem. 2003, 41, 2297-2303.

(41) Sehmi, S. K.; Noimark, S.; Bear, J. C.; Peveler, W. J.; Bovis, M.; Allan, E.; MacRobert, A. J.; Parkin, I. P. Lethal Photosensitisation of Staphylococcus aureus and Escherichia coli Using Crystal Violet and Zinc
Oxide-Encapsulated Polyurethane. J. Mater. Chem. B 2015, 3, 64906500.

(42) Ozkan, E.; Allan, E.; Parkin, I. P. The Antibacterial Properties of Light-Activated Polydimethylsiloxane Containing Crystal Violet. RSC Adv. 2014, 51711-51715.

(43) Zhang, L.; Jiang, Y.; Ding, Y.; Povey, M.; York, D. Investigation into the Antibacterial Behaviour of Suspensions of $\mathrm{ZnO}$ Nanoparticles (ZnO Nanofluids). J. Nanopart. Res. 2007, 9, 479-489.

(44) Tayel, A. A.; El-Tras, W. F.; Moussa, S.; El-Baz, A. F.; Mahrous, H.; Salem, M. F.; Brimer, L. Antibacterial Action of Zinc Oxide Nanoparticles Against Foodborne Pathogens. J. Food Saf. 2011, 31, 211-218.

(45) Gracanin, M.; Hawkins, C. L.; Pattison, D. I.; Davies, M. J. Singlet-Oxygen-Mediated Amino Acid and Protein Oxidation: Formation of Tryptophan Peroxides and Decomposition Products. Free Radical Biol. Med. 2009, 47, 92-102.

(46) Noimark, S.; Dunnill, C. W.; Kay, C. W. M.; Perni, S.; Prokopovich, P.; Ismail, S.; Wilson, M.; Parkin, I. P. Incorporation of Methylene Blue and Nanogold into Polyvinyl Chloride Catheters; a New Approach for Light-Activated Disinfection of Surfaces. J. Mater. Chem. 2012, 22, 15388.

(47) Perni, S.; Piccirillo, C.; Pratten, J.; Prokopovich, P.; Chrzanowski, W.; Parkin, I. P.; Wilson, M. The Antimicrobial Properties of Light-Activated Polymers Containing Methylene Blue and Gold Nanoparticles. Biomaterials 2009, 30, 89-93.

(48) Li, Q.; Mahendra, S.; Lyon, D. Y.; Brunet, L.; Liga, M. V.; Li, D.; Alvarez, P. J. J. Antimicrobial Nanomaterials for Water Disinfection and Microbial Control: Potential Applications and Implications. Water Res. 2008, 42, 4591-4602.

(49) Hirota, K.; Sugimoto, M.; Kato, M.; Tsukagoshi, K.; Tanigawa, T.; Sugimoto, H. Preparation of Zinc Oxide Ceramics with a Sustainable Antibacterial Activity under Dark Conditions. Ceram. Int. 2010, 36, 497-506.

(50) Joshi, P.; Chakraborti, S.; Chakrabarti, P.; Haranath, D.; Shanker, V.; Ansari, Z. A.; Singh, S. P.; Guptas, V. Role of Surface Adsorbed Anionic Species in Antibacterial Activity of $\mathrm{ZnO}$ Quantum Dots against Escherichia coli. J. Nanosci. Nanotechnol. 2009, 9, 64276433.

(51) Sawai, J.; Yoshikawa, T. Quantitative Evaluation of Antifungal Activity of Metallic Oxide Powders ( $\mathrm{MgO}, \mathrm{CaO}$ and $\mathrm{ZnO}$ ) by an Indirect Conductimetric Assay. J. Appl. Microbiol. 2004, 96, 803-809.

(52) Premanathan, M.; Karthikeyan, K.; Jeyasubramanian, K.; Manivannan, G. Selective Toxicity of $\mathrm{ZnO}$ Nanoparticles toward Gram-Positive Bacteria and Cancer Cells by Apoptosis through Lipid Peroxidation. Nanomedicine 2011, 7, 184-192.

(53) Li, M.; Pokhrel, S.; Jin, X.; Mädler, L.; Damoiseaux, R.; Hoek, E. M. V. Stability, Bioavailability, and Bacterial Toxicity of $\mathrm{ZnO}$ and IronDoped $\mathrm{ZnO}$ Nanoparticles in Aquatic Media. Environ. Sci. Technol. 2011, 45, 755-761.

(54) Heinlaan, M.; Ivask, A.; Blinova, I.; Dubourguier, H.-C.; Kahru, A. Toxicity of Nanosized and Bulk $\mathrm{ZnO}, \mathrm{CuO}$ and $\mathrm{TiO} 2$ to Bacteria Vibrio fischeri and Crustaceans Daphnia magna and Thamnocephalus platyurus. Chemosphere 2008, 71, 1308-1316.

(55) Jones, N.; Ray, B.; Ranjit, K. T.; Manna, A. C. Antibacterial Activity of $\mathrm{ZnO}$ Nanoparticle Suspensions on a Broad Spectrum of Microorganisms. FEMS Microbiol. Lett. 2008, 279, 71-76.

(56) Sapkota, A.; Anceno, A. J.; Baruah, S.; Shipin, O. V.; Dutta, J. Zinc Oxide Nanorod Mediated Visible Light Photoinactivation of Model Microbes in Water. Nanotechnology 2011, 22, No. 215703.

(57) Yin, H.; Casey, P. S.; McCall, M. J.; Fenech, M. Effects of Surface Chemistry on Cytotoxicity, Genotoxicity, and the Generation of Reactive Oxygen Species Induced by $\mathrm{ZnO}$ Nanoparticles. Langmuir 2010, 26, 15399-15408.

(58) Perelshtein, I.; Applerot, G.; Perkas, N.; Wehrschetz-Sigl, E.; Hasmann, A.; Guebitz, G. M.; Gedanken, A. Antibacterial Properties of an in Situ Generated and Simultaneously Deposited Nanocrystalline $\mathrm{ZnO}$ on Fabrics. ACS Appl. Mater. Interfaces 2009, 1, 361-366.

(59) Lakshmi Prasanna, V.; Vijayaraghavan, R. Insight into the Mechanism of Antibacterial Activity of ZnO: Surface Defects Mediated 
Reactive Oxygen Species Even in the Dark. Langmuir 2015, 31, 91559162.

(60) Antibiotic Resistance Threats in the United States; Centers for Disease Control and Prevention, U.S. Department of Health and Human Services: Atlanta, GA, 2013.

(61) Jones, N.; Ray, B.; Ranjit, K. T.; Manna, A. C. Antibacterial Activity of $\mathrm{ZnO}$ Nanoparticle Suspensions on a Broad Spectrum of Microorganisms. FEMS Microbiol. Lett. 2008, 279, 71-76.

(62) Noimark, S.; Dunnill, C. W.; Wilson, M.; Parkin, I. P. The Role of Surfaces in Catheter-Associated Infections. Chem. Soc. Rev. 2009, 38, 3435.

(63) Hong, T.-K.; Tripathy, N.; Son, H.-J.; Ha, K.-T.; Jeong, H.-S.; Hahn, Y.-B. A Comprehensive in Vitro and in Vivo Study of $\mathrm{ZnO}$ Nanoparticles Toxicity. J. Mater. Chem. B 2013, 1, 2985.

(64) Reddy, K. M.; Feris, K.; Bell, J.; Wingett, D. G.; Hanley, C.; Punnoose, A. Selective Toxicity of Zinc Oxide Nanoparticles to Prokaryotic and Eukaryotic Systems. Appl. Phys. Lett. 2007, 90, No. 213902. 